\title{
Participation in Mind-Body-Spirit Programs and Length of Stay in a Residential Addiction Treatment Facility: A Retrospective Analysis
}

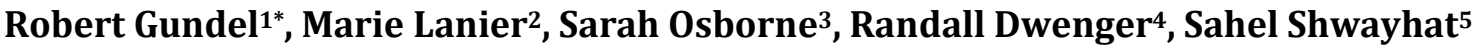 \\ ${ }^{1}$ Departments of Outcomes Measures, Mountainside Treatment Center, Canaan, CT, USA \\ ${ }^{2}$ Program Development, Mountainside Treatment Center, Canaan, CT, USA \\ ${ }^{3}$ Clinical Operations, Mountainside Treatment Center, Canaan, CT, USA \\ ${ }^{4}$ Medical Psychiatry, Mountainside Treatment Center, Canaan, CT, USA \\ ${ }^{5}$ Operations, Mountainside Treatment Center, Canaan, CT, USA \\ Email: *bob.gundel@mountainside.com
}

How to cite this paper: Gundel, R., Lanier, M., Osborne, S., Dwenger, R. and Shwayhat, S. (2017) Participation in Mind-BodySpirit Programs and Length of Stay in a Residential Addiction Treatment Facility: A Retrospective Analysis. Open Journal of Medical Psychology, 6, 103-114.

https://doi.org/10.4236/ojmp.2017.62008

Received: March 14, 2017

Accepted: April 18, 2017

Published: April 21, 2017

Copyright $\odot 2017$ by authors and Scientific Research Publishing Inc. This work is licensed under the Creative Commons Attribution International License (CC BY 4.0).

http://creativecommons.org/licenses/by/4.0/

\begin{abstract}
Length of stay in treatment is thought to be the best predictors for long-term recovery from substance use disorders. The objective of this study was to examine the relationship between participation in mind-body-spirit (MBS) therapeutic programs and length of stay in a residential treatment facility. A retrospective analysis of data from 1719 subjects who were admitted to a 30-day residential program for substance use disorders (SUD) was conducted. Subjects participated in MBS programs that included yoga, acupuncture and meditation. We examined the effects of subject participation in MBS programs for subjects who left against staff advice (ASA) and those who successfully completed the residential program. A higher percentage of subjects with severe heroin use disorder left ASA compared with subjects with severe alcohol use disorder ( $16 \%$ vs. $9 \%$, respectively). Most subjects from both substance groups who failed to complete the 30-day treatment program, left within the first two weeks of stay (59\% of alcohol group and $75 \%$ of heroin group); however, again, the percentage of heroin users leaving during the first two weeks was significantly greater compared with that of alcohol subjects. We found a highly significant, positive correlation $(\mathrm{r}=0.56, \mathrm{p}<0.01)$ and a statistically significant increase in LOS for all subjects, regardless of the substance type, and the number of MBS program sessions attended showing an association between MBS participation and increased LOS. These data support the inclusion of MBS programs as part of a comprehensive treatment strategy for SUD in combination with traditional counseling to help develop a sustainable long-term recovery.
\end{abstract}

\section{Keywords}

Substance Use Disorder, Length of Stay, Residential Treatment Facility, 
Mind-Body-Spirit Programs

\section{Introduction}

Substance use disorder (SUD) is a major public health concern in the US. Recent numbers published by SAMHSA indicate that of the $22.7 \mathrm{M}$ people who need treatment for the substance use disorder, only about $2.5 \mathrm{M}(\sim 10 \%)$ received the treatment [1]. In addition to a public health concern, SUDs also pose a heavy economic burden to the healthcare system and to the workplace [2] [3] [4]. SUD-related emergency department visits involving alcohol and illicit drug misuse are increasing annually and are projected to continue to increase [5] [6]. Estimates of almost $15 \%$ of employed adults have either used alcohol or illicit drugs while at work or while employed, which represents a significant problem impacting workforce productivity and safety [7] [8].

SUD is a chronic, relapse-prone disease and, as such, recovery is a life-long process [9] [10]. Recovery treatment can be viewed as two separate stages; the first stage involves an initial process of detoxification and stabilization followed by some types of the residential program of varying length [11]. During this first stage, there is an acute focus on the health of the individual and dealing with both the physical and emotional symptoms of withdrawal. Once stabilized, the focus can shift to the more cognitive/education directed therapy (depending on the needs of the subject) to gain an understanding of the addictive behavior, incite and develop new coping skills for dealing with potential triggers for substance use. If possible, involving and educating the immediate and extended family about addiction is beneficial and helps to establish a solid support group and ensure old familial patterns don't hinder progress. The second stage of recovery is a lengthier process and usually includes a limited, less intensive outpatient component in addition to or followed by a community-based support program such as alcoholics anonymous. The focus of the second stage is on maintaining a healthy, substance-free lifestyle while continuing to practice existing coping skills and learning new skills enabling a successful re-engagement in community and a productive, meaningful life.

Mind, body, spirit (MBS) programs are designed to provide subjects with meaningful therapeutic experiences that promote a greater sense of self-awareness and personal growth to foster the development of holistic coping skills. MBS utilizes several tools including yoga, acupuncture, relaxation techniques and meditation and is widely used along with more traditional clinical approaches. MBS programs are thought to be important in both stages of recovery as a helpful adjunct for symptoms of substance withdrawal in the short term and as a means of gaining a greater sense of wellbeing and emotional symptom management and spirituality over the long term.

Studies have shown that one of the best predictors of long-term recovery is the LOS in SUD treatment [12] [13]. Interestingly, this observation appears to be a 
consistent finding despite variations in treatment approaches and specific programs included as a part of treatment [14]. MBS related programs have the potential to be important components for a successful short and long-term recovery program.

Here we report the results of a retrospective analysis examining the potential benefit of MBS programs included as part of a comprehensive treatment program for subjects in a 30-day residential program.

\section{Methods}

\subsection{Sample Population}

Subjects included in this retrospective study represent all comers to a 30-day residential addiction treatment facility between January 2011 and June 2016 who were in treatment for either alcohol or heroin addiction. Subject demographics, substance use, treatment history and related information was obtained upon admission to the facility and stored in an electronic medical record database. Subjects leaving residential treatment after less than or equal to 27 days against staff advice were considered early discharges. Those completing 28 days or more were considered as completing residential treatment. All data was obtained from the EMR database and assembled and organized using Microsoft Access ${ }^{\mathrm{TM}}$ and imported into Microsoft Excel $^{\text {sis }}$ for analysis. All protocols for data collection, storage, and analysis were reviewed and approved by an independent review board (Regulatory and Technical Associates, Old Lyme, CT).

\subsection{Treatment}

The services were provided by licensed clinicians, MBS practitioners, and licensed acupuncturists and included a blend of traditional treatments such as cognitive-behavioral, family oriented approaches, individual and group therapy sessions and alternative therapeutic approaches such as acupuncture, deep relaxation, meditation and yoga. Integrated health care was provided on-site including medication management by licensed medical doctors and nurses.

\subsection{MBS Programs and Procedures}

Acupuncture: The National Acupuncture Detoxification Association (NADA) standardized procedures for auricular, group acupuncture was utilized by licensed acupuncturists. Subjects received acupuncture at 5 ear points specific for drug dependency: Sympathetic, Shenmen (Spirit), Kidney, Liver and Lung. Sterile disposable needles were used and all acupuncture points were prepared using an alcohol prep pad. Needles were left in approximately 30 minutes with subjects seated in comfortable reclining chairs with soft lighting and music in the background. Acupuncture sessions were offered three times each week throughout the 30 day stay in the residential program. Subjects also participated in individual, full body acupuncture including a variety of different points depending on symptoms presented to the acupuncturist. For the full body acupuncture sessions, needles were left in for approximately 45 minutes. Subjects 
typically had 1 - 2 full body sessions per treatment stay.

Yoga: Subjects establish a centered position either lying down or sitting as the session begins. Each session contains three basic phases; establishing a focus on the breath, verbal guidance for a gentle muscle warm-up movements and positions followed by several static-hold positional poses. Different poses targeting certain areas (e.g. lower back, core, upper body) are used throughout the 30 - 40minute session.

Meditation: Group meditation begins by subjects establishing a comfortable, seated, upright position with the use of pillows to ensure alignment of the spine and energy flow. A one-word affirmation card is chosen and used as a focal point throughout the meditation session while soft, gentle therapeutic music in the background opens the session. This is followed with a 10 to 12-minute narration using metaphors and analogy to relax the mind and body while quieting thoughts using the breath technique and focal point to remain in that space.

\subsection{Data Collection and Analysis}

All data were collected and recorded in an electronic database. Data were pulled from the electronic medical files, summarized and analyzed using Microsoft Excel and MiniTab ${ }^{\text {Tw }}$ analytic software. Data from each group were compared using a paired $\mathrm{t}$-Test analysis. A p value of less than or equal to 0.05 was considered statistically significant. The correlation analysis was conducted using the linear regression tool in the Excel data analysis software. Data on average number of MBS sessions were not normally distributed and nonparametric statistical tests were used for analysis between groups. The calculations of normalized, average number of MBS sessions per LOS were done by determining the average LOS for each group (e.g. 12.2 days for the alcohol subjects and 9.6 days for the heroin subjects), determining the average number of MBS sessions per day for each group and then multiplying this by the average LOS.

\section{Results}

\subsection{Sample Characteristics}

This study included 1719 adult subjects who were admitted to a 30-day residential addiction treatment program between January 2011 and June 2016 (Table 1 ). There was a greater percentage of male versus female subjects (1134 or $66 \%$ vs. 585 or $34 \%$ ). Of these subjects, 1075 were diagnosed with severe alcohol use disorder and 644 were diagnosed with severe opioid use disorder with a primary substance of heroin. Over this five and one-half year period, 1521 successfully completed the residential program while 198 left against staff advice (ASA). Of those subjects who successfully completed the program, 978 and 543 were in treatment for severe alcohol and severe opioid use disorder, respectively. Of the 198 subjects who left ASA, 97 were diagnosed with severe alcohol use disorder and 101 were diagnosed with severe opioid use disorder with heroin as the primary substance. 
Table 1. Subject demographic information and treatment completion status.

\begin{tabular}{cccc}
\hline Variable & Number of Subjects & Age, Mean \pm SD & ASA, Completed (\% ASA) \\
\hline All Subjects & 1719 & $33 \pm 13$ & $198,1521(11 \%)$ \\
Male & 1134 & $33 \pm 9$ & $125,1134(11 \%)$ \\
Female & 585 & $37 \pm 12$ & $56,529(10 \%)$ \\
Alcohol & 1075 & $41 \pm 12$ & $97,978,(9 \%)$ \\
Male & 654 & $39 \pm 7$ & $58,596(9 \%)$ \\
Female & 421 & $43 \pm 8$ & $28,393(7 \%)$ \\
Heroin & 644 & $24 \pm 6$ & $101,543(16 \%)$ \\
Male & 485 & $25 \pm 5$ & $72,413(15 \%)$ \\
Female & 159 & $23 \pm 4$ & $29,130(18 \%)$ \\
\hline
\end{tabular}
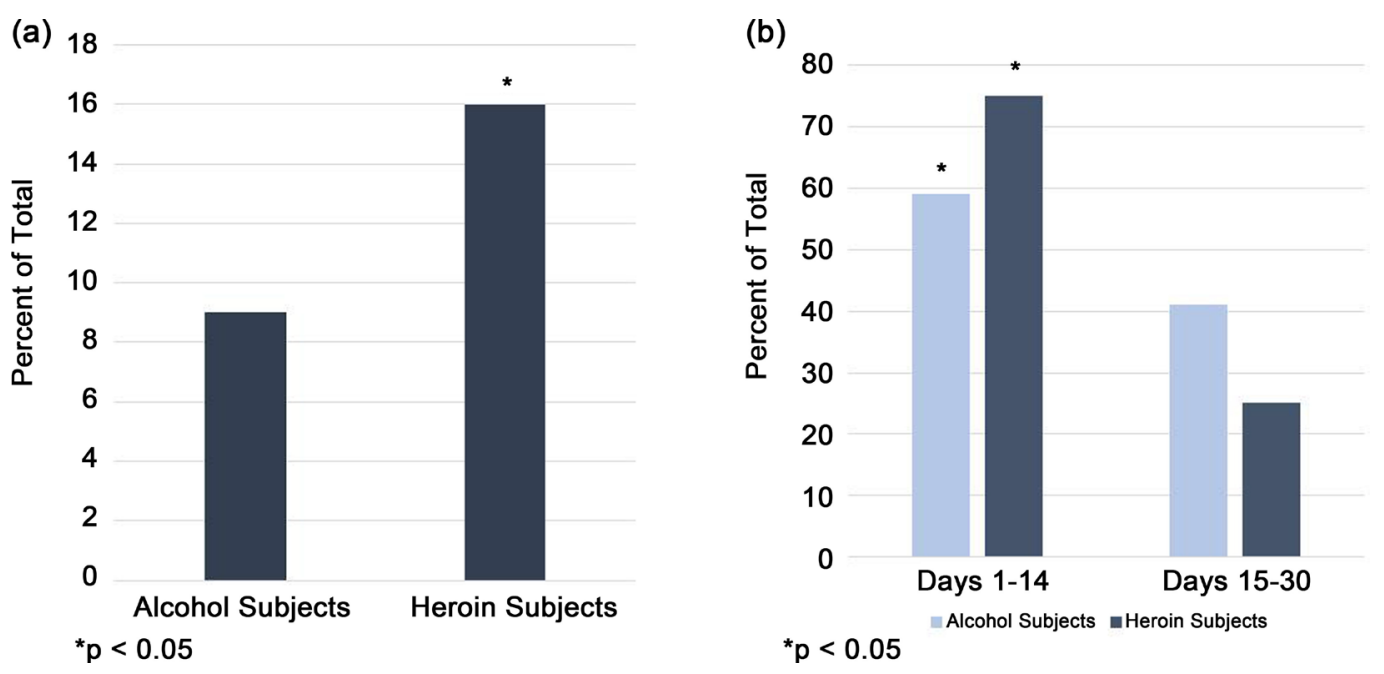

Figure 1. The percentage of subjects leaving the 30-day residential treatment facility against staff advice. (a) The percentage of subjects from the heroin group leaving ASA is significantly higher compared to the alcohol subject group. (b) Of those subjects who left treatment ASA, most left the program within the first two weeks. Again, the percentage of subjects from the heroin group was significantly greater compared to subjects from the alcohol group. Data expressed as the percent of total subjects in each substance group. ${ }^{*} \mathrm{p}<0.05$. Fischer's Exact Test. $\mathrm{n}=97$ alcohol group, $\mathrm{n}=101$ heroin group.

\subsection{Early Discharge Analysis}

The percentage of subjects leaving ASA was significantly greater in the heroin group compared to the alcohol group, $16 \%$ and $9 \%$ respectively, $\mathrm{p}<0.05$ (Figure 1). A time analysis showed that while most subjects from both groups who failed to complete the 30-day treatment program left within the first two weeks (59\% of the alcohol subjects and $75 \%$ of the heroin), the percentage of heroin group subjects leaving during the first two weeks of treatment was significantly greater compared to the alcohol group. The percentage of subjects leaving during the second half of the residential program was significantly less than compared to the first two weeks ( $41 \%$ for the alcohol subjects and $25 \%$ for the heroin subjects).

\subsection{Impact of MBS Programs}

We examined the impact of participation in MBS programs on LOS in residen- 
tial treatment. Our results show that increased participation in MBS programs was associated with a statistically significant increase in LOS (Figure 2). Subjects who participated in a greater number of MBS programs stayed in residential treatment longer. This observation is further supported by linear regression analysis which revealed a significant correlation between LOS and the number of sessions of MBS programs (Figure 3).

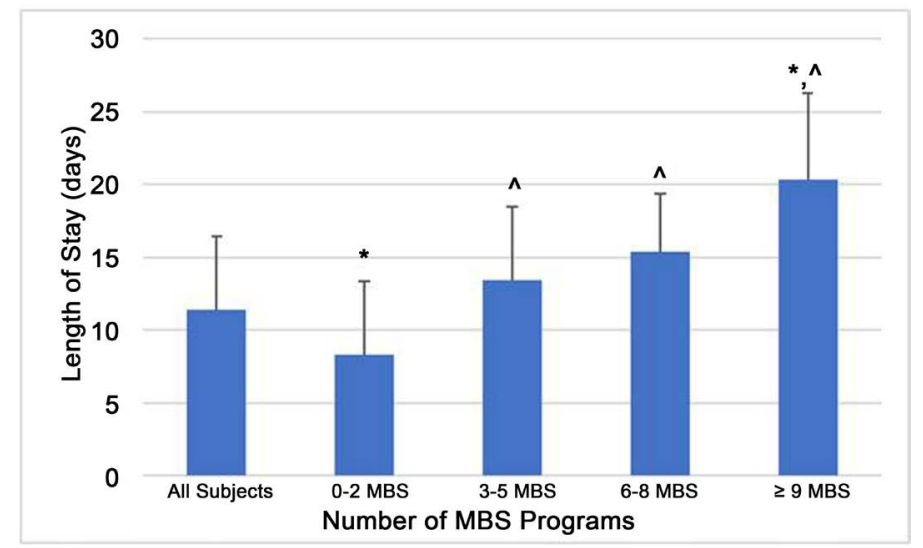

$\left({ }^{\star} \mathrm{p}<0.05\right.$ compared to all MBS group; ${ }^{\wedge} \mathrm{p}<0.05$ compared to $(0-2 \mathrm{MBS})$ group)

Figure 2. Length of stay (days) for all ASA subjects and their participation in MBS programs. MBS program participation is grouped as follows: (all subjects) are all subjects regardless of the number of MBS programs they participated in; (0 - $2 \mathrm{MBS})$ are subjects who participated in 2 or fewer program sessions, (3 - $5 \mathrm{MBS}$ ) are subjects who participated at least 3 but no more than $5 \mathrm{MBS}$ programs, $(6-8 \mathrm{MBS})$ are subjects who participated in at least 6 sessions but no more than 8 and ( $>9 \mathrm{MBS}$ ) are subjects who participated in at least 9 or greater MBS programs. There was a significant increase in the number of days in residential treatment associated with increasing participation in MBS programs.

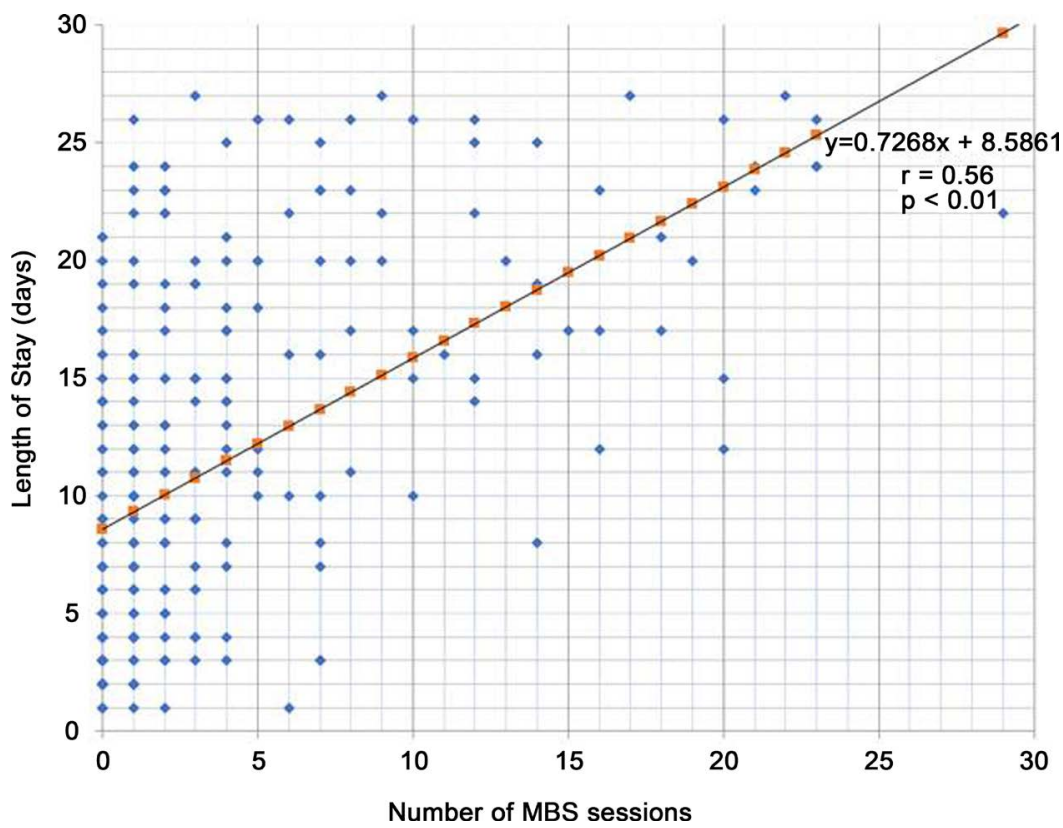

Figure 3. Regression analysis and correlation of the length of stay (days) in residential and the number of MBS programs for all ASA subject. There was a highly significant correlation for length of stay and participation in MBS programs. 


\subsection{Analysis by Substance}

An analysis of ASA subjects based on substance type revealed no difference between the alcohol and heroin groups for LOS in response to participation in MBS sessions. Subjects in either the alcohol or heroin groups who participated in 3 or more MBS programs had a significantly greater LOS compared to their respective subjects who participated in 2 or fewer sessions (Figure 4). Comparing the average number of MBS sessions per day (normalized as number of MBS sessions per LOS) in subjects who successfully completed the 30-day residential program to those subjects who left ASA showed the same association, however, the difference between the alcohol subjects who completed the program compared to those who left ASA was greater than the difference observed in the heroin subjects (Figure 5(a) and Figure 5(b)).

\section{Discussion and Conclusions}

The objective of this retrospective analysis was to examine the impact of MBS programs on LOS and the ability of subjects to complete a 30-day residential addiction treatment program.

We observed a difference between substance groups in terms of propensity to leave residential treatment ASA. While most subjects from both substance groups left within the first two weeks of residential treatment, a significantly greater percentage of subjects from the heroin group left the treatment ASA during the first two weeks compared to subjects from the alcohol group.

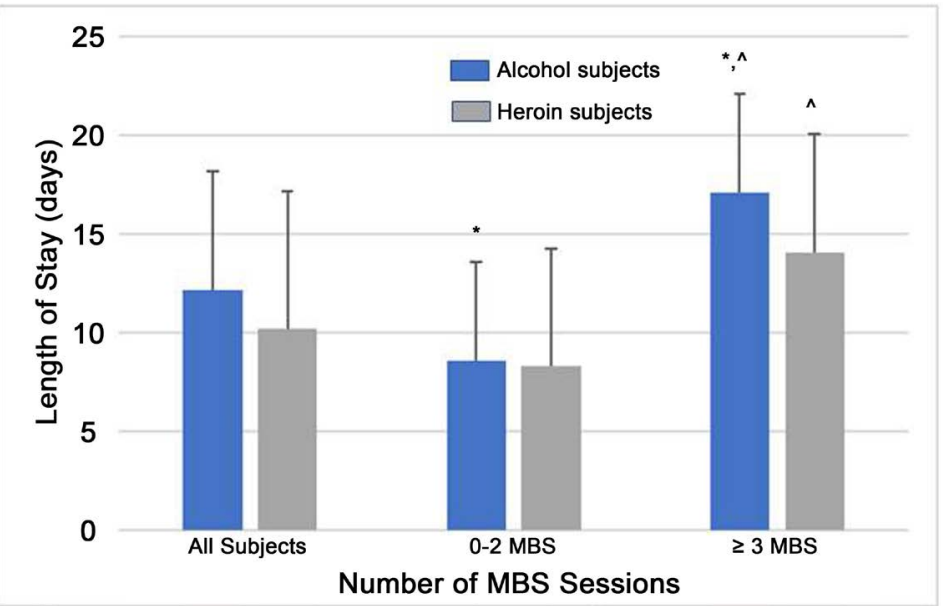

Figure 4. Length of stay (days) for all ASA subjects in the heroin group and alcohol group and their participation in MBS programs. MBS program participation is grouped as follows: (all subjects) are all subjects regardless of the number of MBS programs they participated in; (0 - $2 \mathrm{MBS}$ ) are subjects, who participated in 2 or fewer program sessions, (>3 MBS) are subjects who participated at least 3 or greater MBS programs. In the alcohol group, the LOS was significantly lower in the 0 - 2 MBS group compared to the all MBS group and the $>3 \mathrm{MBS}$ group was significantly greater to both the all subjects and $0-2$ MBS groups. In the heroin group, there was no statistically significant difference in LOS between the all subject group and the $0-2 \mathrm{MBS}$ group and the $>3 \mathrm{MBS}$ group. The length of stay for the $>3 \mathrm{MBS}$ group was statistically greater compared to the $0-2 \mathrm{MBS}$ group $(\wedge \mathrm{p}<0.05$ compared to the $0-2$ MBS group). 
(a)

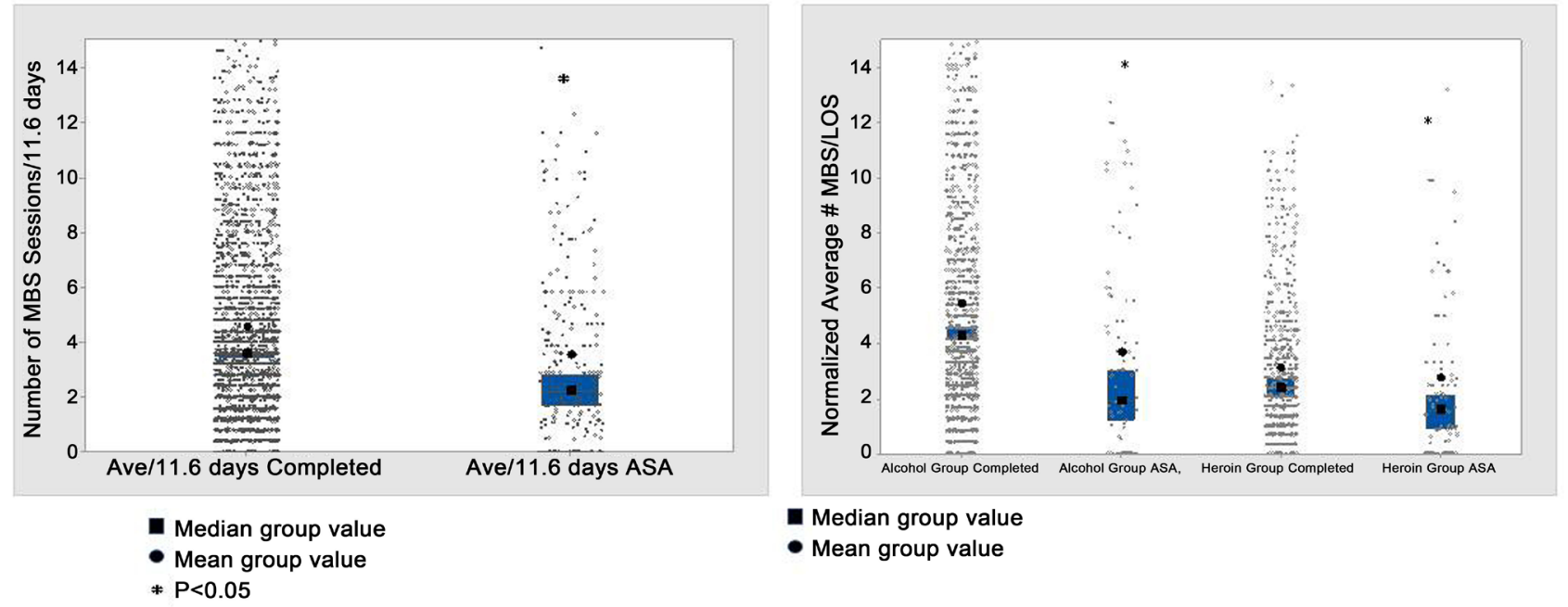

Figure 5. (a) A comparison of the number of MBS sessions for subjects who completed the 30-day residential program and subjects who left ASA. For a valid comparison between the groups, the data were normalized to the average LOS for the ASA group (11.6 days). The subjects who completed the program had a significantly greater number of MBS sessions compared to subjects who left the program ASA. (b) The number of MBS sessions per day for subjects from each substance group who left ASA versus those subjects who completed the 30-day residential program. There are a significantly greater number of MBS sessions per day (adjusted for LOS) in the alcohol and heroin subjects who completed the residential program compared to subjects who left the program ASA.

These data, combined with our data showing that a greater overall percentage of subjects from the heroin left treatment ASA, indicate that subjects in treatment for heroin addiction are at higher risk for leaving a residential treatment facility ASA compared to subjects in treatment for alcohol addiction.

We also examined the impact of MBS programs on LOS in the residential addiction treatment program. Our result show that subjects who are more involved in MBS programs, as measured by the average number of sessions attended, were more likely to complete the 30-day residential program. This observation held true regardless of substance use type. There was a significantly greater average number of MBS sessions per LOS attended in each substance group who completed the 30-day program compared to those who left the program ASA.

MBS programs have become a mainstream part of addiction treatment and are used in combination with more traditional types of individual and group therapy. MBS programs are designed to promote meaningful, introspective thinking and therapeutic experiences to increase self-awareness, mindfulness and spirituality as an adjunct for the development of new coping skills. MBS utilizes several mindfulness and wellness tools including yoga, acupuncture, relaxation techniques and meditation. A review of the literature shows a paucity of well conducted clinical studies designed to evaluate the effectiveness of MBS-related therapy in addiction treatment [15] [16]; however, there is substantial anecdotal evidence to support its use in conjunction with more traditional therapy. Our study results suggest a potentially important role for MBS programs in addiction treatment and different responses based on the type of substance used.

LOS in treatment is generally regarded as one of the best predictors of long- 
term recovery [17]. The longer one remains in treatment, residential, outpatient or a combination of both, the greater chance one has of achieving a sustainable recovery from SUD. Our data show that subjects who are more involved in MBS therapy have a greater chance of making it through a residential treatment program and achieving long-term recovery.

Early studies have shown that subjects that have at least 3 months of treatment demonstrate significantly better recovery as measured by several parameters including substance use, trouble with law enforcement and employment [17]. With this knowledge in mind, more recent studies have focused on identifying extraneous factors as well as subject characteristics that may contribute to an inability to remain focused on recovery and, in part, leading to a relapse [18] [19] [20] [21]. The identification of important circumstances, predispositions and other factors could be used to identify subjects most at risk for leaving treatment early and allow for the development of an individualized treatment plan that is designed to address these factors and maximize the chance of completing treatment.

Co-occurring mental health disorders have been shown to be associated with both increased ASA and relapse rates in subjects with SUD [9]-[22]. Studies have shown that female alcoholics had approximately a four times greater rate of depression compared to non-alcoholic females while male alcoholics had a three times greater rate [23] [24]. We have previously reported that a high percentage of subjects entering a 30-day addiction treatment center had anxiety, substance craving and depression scores above threshold levels considered clinically relevant (Gundel, R.H., unpublished). Thus, treatment of co-occurring disorders such as anxiety and depression need to be included as part of the SUD recovery plan.

MBS programs have long been thought to help with a variety of mental and physical conditions. Support for the use of MBS programs in addiction treatment comes from anecdotal evidence and a growing clinical literature (reviewed in 16). Clinical studies have produced somewhat equivocal results; however, there are several studies that show beneficial effects of acupuncture on several co-occurring mental health issues such as depression, anxiety and other withdrawal symptoms in subjects in recovery [25]. Mindfulness based therapy including yoga and meditation have also been examined in clinical studies and shown to be helpful with reducing co-occurring symptoms such as depression and substance craving [26] [27].

In a previous study, we found that MBS programs were helpful in reducing symptoms present in co-occurring disorders (Gundel, R.H., unpublished). High levels of anxiety, substance craving and depressions were quickly reduced below threshold levels in subjects in treatment for severe alcohol or opioid/heroin use disorder. We speculate that the results obtained in the current study reflex, in part, the positive effects of MBS program therapy on mental health symptoms. MBS programs teach subjects various techniques that allow them to exercise more self-control and a greater ability to focus on their recovery effort leading to 
a successful completion of a 30-day program. Our results showing that subjects who completed the 30-day residential program had a significant greater number of MBS sessions compared to those subjects who left ASA supports our contention. Our analysis was done using the average number of MBS sessions per day and normalized for the LOS for each subject group which allows a valid comparison the data between groups.

In addition to anxiety, substance craving and depression, there are undoubtedly other important factors that may lead to subjects leaving treatment ASA. For example, numerous studies have shown that age is an important determinant as younger subjects are more likely to leave treatment ASA compared to older subjects [28] [29]. Our results support this finding in the following way. We found that a greater percentage of subjects in treatment for severe opio$\mathrm{id} /$ heroin use disorder left ASA compared to subjects in treatment for severe alcohol use disorder (16\% vs. $9 \%)$. The average age of the heroin/opioid use disorder group was significantly lower compared to the average age of the alcohol use disorder group ( $24 \pm 6$ vs. $41 \pm 12$ years, respectively; $\mathrm{p}<0.05$ ). Additional factors may include other types of co-occurring disorders such as bipolar disease, Attention Deficit and Hyperactivity Disorder, Post-Traumatic Stress Disorder and personality disorders. These conditions are beyond the scope of the current investigation but will be the subject of additional prospective studies in the future.

\section{Conclusion}

The results of our retrospective analysis support the importance of integrating MBS related therapy programs into a comprehensive addiction treatment approach. We found a significant correlation between participation in MBS programs and LOS in a residential treatment facility. Consequently, subjects who participated to a greater level in MBS programs had a greater success rate in terms of completing a 30-day residential SUD treatment program.

\section{Acknowledgements}

The authors wish to acknowledge the help of Normand Allen III for his expert data specialist skills and David Matteini, Roy Sasenaraine, Alex Helfer and Martin Fedor for their helpful review of the manuscript.

\section{References}

[1] Substance Abuse and Mental Health Services Administration (2013) National Survey of Substance Treatment Services (N-SSATS). Data on Substance Abuse Treatment Facilities.

[2] Cherpitel, C.J., Ye, Y., Bond, J., Gorges, G. and Monteiro, M. (2015) Relative Risk of Injury from Acute Alcohol Consumption: Modeling the Does-Response Relationship in Emergency Department Data from 18 Countries. Addiction, 11, 279-288. https://doi.org/10.1111/add.12755

[3] Lim, S., Vos, T., Flaxman, A., Danaei, G., Shibuya, K., Adair-Rohani, H., et al. (2012) A Comparative Risk Assessment of Burden of Disease and Injury Attributa- 
ble to 67 Risk Factor Clusters in 21 Regions, 1990-2010: A Systemic Analysis for Global Burden of Disease Study 2010. The Lancet, 380, 2224-2260. https://doi.org/10.1016/S0140-6736(12)61766-8

[4] Anzai, Y., Kuriyama, S., Nishino, Y., Takahashi, K., Takayoshi, O., Ohmori, K., Tsubono, Y. and Tsuji, I. (2005) Impact of Alcohol Consumption upon Medical Care Utilization and Costs in Men: 4-Year Observation of National Health Insurance Beneficiaries in Japan. Addiction, 100, 19-27. https://doi.org/10.1111/j.1360-0443.2004.00874.x

[5] McDonald, A.J., Wang, N. and Camargo, C.A. (2004) US Emergency Department Visits for Alcohol-Related Diseases and Injuries between 1992 and 2000. Archives of Internal Medicine, 164, 531-537. https://doi.org/10.1001/archinte.164.5.531

[6] Cherpitel, C.J., Ye, Y., Bond, J., Gorges, G., Monteiro, M., Chou, P. and Hao, W. (2015) Alcohol Attributable Fraction for Injury Morbidity from the Dose-Response Relationship of Acute Alcohol Consumption: Emergency Department Data from 18 Countries. Addiction, 110, 1724-1732. https://doi.org/10.1111/add.13031

[7] Frone, M. (2006) Prevalence and Distribution of Alcohol Use and Impairment in the Workplace: A U.S. National Survey. Journal of Studies on Alcohol and Drugs, 67, 147-156. https://doi.org/10.15288/jsa.2006.67.147

[8] Frone, M. (2006) Prevalence and Distribution of Illicit Drug Use in the Workforce and in the Workplace: Findings and Implications from a U.S. National Survey. Journal of Applied Psychology, 91, 856-869. https://doi.org/10.1037/0021-9010.91.4.856

[9] Littman, G., Stapleton, J., Oppenheim, A., Peleg, M. and Jackson, P. (1983) Situations Related to Alcoholism Relapse. Addiction, 78, 381-389. https://doi.org/10.1111/j.1360-0443.1983.tb02526.x

[10] Hendershot, C., Witkiewitz, K., George, W. and Marlatt, G. (2011) Relapse Prevention for Addictive Behaviors. Substance Abuse Treatment, Prevention, and Policy, 6, 17-34. https://doi.org/10.1186/1747-597X-6-17

[11] Proctor, S. and Herschman, P. (2014) The Continuing Care Model of Substance Use Treatment: What Works, and When Is "Enough", "Enough"? Psychiatry, 2014, Article ID: 692423. https://doi.org/10.1155/2014/692423

[12] Simpson, D. (1981) Treatment for Drug Abuse: Follow-Up Outcomes and Length of Time Spent. Archives of General Psychiatry, 38, 875-880. https://doi.org/10.1001/archpsyc.1981.01780330033003

[13] Zang, Z., Friedmann, P. and Gerstein, D. (2003) Does Retention Matter? Treatment Duration and Improvement in Drug Use. Addiction, 98, 673-684. https://doi.org/10.1046/j.1360-0443.2003.00354.x

[14] Simpson, D., Joe, G., Broome, K., Hiller, M., Knight, K. and Roway-Szal, G. (1997) Program Diversity and Treatment Retention Rates in the Drug Abuse Treatment Outcome Study (DATOS). Psychology of Addictive Behaviors, 11, 279-293. https://doi.org/10.1037/0893-164X.11.4.279

[15] Zgierska, A., Rabago, D., Chawla, N., Kushner, K., Koehler, R. and Marlatt, A. (2009) Mindfulness Meditation for Substance Use Disorders: A Systematic Review. Substance Abuse, 30, 266-294. https://doi.org/10.1080/08897070903250019

[16] Motlagh, F., Ibrahim, F., Rashid, R., Seghatoleslam, T. and Habil, H. (2016) Acupuncture Therapy for Drug Addiction. Chinese Medicine, 11, 16-36. https://doi.org/10.1186/s13020-016-0088-7

[17] Hubbard, R., Craddock, S., Flynn, P., Anderson, J. and Etheridge, R. (1997) Overview of 1-Year Follow-Up Outcomes in the Drug Abuse Treatment Outcome Study (DATOS). Psychology of Addictive Behaviors, 11, 261-278. 
https://doi.org/10.1037/0893-164X.11.4.261

[18] Meuser, K., Noordsy, D., Drake, R. and Fox, L. (2003) Integrated Treatment for Dual Disorders: A Guide to Effective Practice. The Guilford Press, New York.

[19] Weiss, R., Griffin, M., Lolodziej, M., Greenfirld, S., Najavits, L., Daley, D., et al. (2007) A Randomized Trial of Integrated Group Therapy versus Group Drug Counseling for Patients with Bipolar Disorder and Substance Dependence. The American Journal of Psychiatry, 164, 100-107. https://doi.org/10.1176/ajp.2007.164.1.100

[20] Nunes, E. and Levin, F. (2004) Treatment of Depression in Patients with Alcohol or Other Drug Dependence. JAMA, 291, 1887-1896.

https://doi.org/10.1001/jama.291.15.1887

[21] McGovern, M., Xie, H., Segal, S., Siembab, L. and Drake, R. (2006) Addiction Treatment Services and Co-Occurring Disorders: Prevalence Estimates, Treatment Practices, and Barriers. Journal of Substance Abuse Treatment, 31, 267-275. https://doi.org/10.1016/j.jsat.2006.05.003

[22] Cummings, C., Gordon, J. and Marlatt, G. (1980) Relapse: Prevention and Prediction. In: Miller, W.R., Ed., The Addictive Behaviors: Treatment of Alcoholism, Drug Abuses, Smoking and Obesity, Pergamon Press, New York, 291-321.

[23] Kessler, R. and Merikangas, K. (1997) The National Comorbidity Survey Replication (NCS-R): Background and Aims. International Journal of Methods in Psychiatric Research, 13, 60-68. https://doi.org/10.1002/mpr.166

[24] Swendsen, J. and Merikangas, K. (2000) The Comorbidity of Depression and Substance Use Disorders. Clinical Psychology Reviews, 20, 173-189.

[25] Zhang, B., Chen, Y., Cheng, K., Shen, X. and Liu, S. (2014) Efficacy of Acupuncture for Psychological Symptoms Associated with Opioid Addiction: A Systematic Review and Meta-Analysis. Evidence-Based Complementary and Alternative Medicine, 2014, Article ID: 313549. https://doi.org/10.1155/2014/313549

[26] Asl, N.H. and Barahmand, U. (2014) Effectiveness of Mindfulness-Based Cognitive Therapy for Co-Morbid Depression in Drug-Dependent Males. Archives of Psychiatric Nursing, 28, 314-318. https://doi.org/10.1016/j.apnu.2014.05.003

[27] Khanna, S. and Greeson, J. (2013) A Narrative Review of Yoga and Mindfulness as Complementary Therapies for Addiction. Complementary Therapies in Medicine, 21, 244-252. https://doi.org/10.1016/j.ctim.2013.01.008

[28] Greenberg, W., Otero, J. and Villaneuva, L. (1994) Irregular Discharges from a Dual Diagnosis Unit. The American Journal of Drug and Alcohol Abuse, 20, 255-371. https://doi.org/10.3109/00952999409106020

[29] Heissen, R. and McGlashan, T. (1998) Predicting Hospital Discharges Status for Patients with Schizophrenia, Schizoaffective Disorder, Borderline Personality Disorder and Unipolar Affective Disorder. Archives of General Psychiatry, 45, 353-360. https://doi.org/10.1001/archpsyc.1988.01800280069009 
Submit or recommend next manuscript to SCIRP and we will provide best service for you:

Accepting pre-submission inquiries through Email, Facebook, LinkedIn, Twitter, etc. A wide selection of journals (inclusive of 9 subjects, more than 200 journals)

Providing 24-hour high-quality service

User-friendly online submission system

Fair and swift peer-review system

Efficient typesetting and proofreading procedure

Display of the result of downloads and visits, as well as the number of cited articles Maximum dissemination of your research work

Submit your manuscript at: http://papersubmission.scirp.org/

Or contact ojmp@scirp.org 